\title{
Analisa Tingkat Pengetahuan Penyuluh Terhadap Program Kostratani di Provinsi Kalimantan Tengah
}

\author{
Astri Anto ${ }^{1 *}$, Andriansyah $^{1}$ \\ ${ }^{1}$ Balai Pengkajian Teknologi Pertanian Kalimantan Tengah \\ *Corresponding author: astrianto2014@gmail.com
}

\begin{abstract}
Abstrak
Komando Strategis Pembangunan Pertanian (Kostratani) merupakan program utama Kementerian Pertanian dalam rangka mendukung tujuan pembangunan pertanian dalam menyediakan pangan bagai penduduk Indonesia, meningkatkan kesejahteraan petani serta meningkatkan ekspor. Dalam rangka meningkatkan kualitas dan pemahaman mengenai Kostratani, dilaksanakan kegiatan temu tugas peneliti penyuluh Badan Penelitian dan Pengembangan Pertanian (Balitbangtan) dengan penyuluh daerah di Provinsi Kalimantan Tengah. Untuk mengetahui efektivitas kegiatan temu tugas dilaksanakan analisis dengan tujuan untuk mengetahui tingkat pengetahuan peserta sebelum dan sesudah pelaksanaan temu tugas. Kegiatan ini dilaksanakan di Aula Balai Pengkajian Teknologi Pertanian (BPTP) Kalimantan Tengah pada tanggal 30-31 Januari 2020. Evaluasi dilakukan kepada seluruh peserta temu tugas yang berjumlah 76 orang penyuluh dari perwakilan 14 kabupaten/kota se-Kalimantan Tengah. Pengumpulan data dilakukan dengan observasi melalui wawancara terstruktur dengan kuesioner. Untuk menguji perbedaan tingkat pengetahuan sebelum dan sesudah temu tugas digunakan uji t-Test. Hasil analisis menunjukkan bahwa tingkat pengetahuan sebelum kegiatan temu tugas sebanyak 40 peserta $(52,63 \%)$ berada pada kategori tinggi dan sesudah temu tugas bertambah menjadi 72 peserta $(94,74 \%)$ dengan nilai rata- rata pre-test 7,55 dan bergeser menjadi 9,26 pada saat post-test dilaksanakan. Hasil uji t-test menunjukkan hasil t Stat 7.26 > t Critical two-tail 1.99, berarti terdapat perbedaan nyata pada pengetahuan responden sebelum dan sesudah diadakan kegiatan temu tugas. Kesimpulan yang diperoleh adalah kegiatan temu tugas peneliti penyuluh Balitbangtan dengan penyuluh daerah telah meningkatkan pengetahuan penyuluh mengenai Kostratani.
\end{abstract}

Kata kunci: Temu tugas Balitbangtan, Penyuluh pertanian, Kostratani, Kalimantan Tengah

\begin{abstract}
The Strategic Command for Agricultural Development (Kostratani) is the Ministry of Agriculture's leading program to support agricultural development goals in providing food for Indonesia's population, improving farmers' welfare, and increasing exports. To improve the quality and understanding of Kostratani, Indonesian Agency for Agricultural Research and Development (IAARD/Balitbangtan) held a task meeting between Balitbangtan's agricultural extension officers and researchers with regional agricultural extension officers in Central Kalimantan Province. This event was held in the hall of the Assessment Institute for Agricultural Technology (AIAT) of Central Kalimantan on 30-31 January 2020. The task meeting's effectiveness was evaluated using an analysis by comparing the participants' level of knowledge before and after the task meeting. The evaluation was carried out on all task meeting participants, totaling 76 agricultural extension officers as representatives of 14 districts /cities in Central Kalimantan. Data collection was carried out through the observation method by structured interviews using a questionnaire. A t-Test was used to examine the differences in knowledge level before and after the task meeting. The results showed that 52.63\% of participants had a high level of knowledge beforehand, and the number subsequently increased to $94.74 \%$ after the task meeting. The average scored increased significantly from 7.55 at the pre-test to 9.26 at the post-test. This finding implies that Balitbangtan agricultural
\end{abstract}


Prosiding Seminar Nasional Pembangunan dan Pendidikan Vokasi Pertanian

Politeknik Pembangunan Pertanian Manokwari, 14 November 2020

e ISSN : 2774-1982

extension officers and researchers' task meetings with regional agricultural extension officers have successfully increased the knowledge of extension officers regarding Kostratani.

Keywords: Balitbangtan task meeting, agricultural extension, Kostratani, Central Kalimantan

\section{PENDAHULUAN}

Hasil Riset FAO, keberhasilan pembangunan pertanian sebanyak 50\% ditentukan oleh aspek sumber daya manusia (petugas pertanian, penyuluh pertanian, praktisi, pengambil kebijakan) yang mengantarkan Indonesia mendapatkan penghargaan FAO pada tahun 1984 dari negara pengimpor beras menjadi negara swasembada beras. Untuk itu penyuluh pertanian di era 4.0 saat ini harus meningkatkan kapasitasnya agar bisa menjadi sumber inspirasi petani yang maju, mandiri dan modern dengan pelayanan penyuluhan yang bekualitas, mudah, tepat dan murah (Nursyamsi, 2020).

Sejak tahun 2019 merupakan tahun Sumber Daya Manusia (SDM), sehingga perlu penguatan kapasitas SDM khususnya pertanian melalui perubahan mindset konvensional menjadi modern serta mampu memanfaatkan teknologi berbasis information technology (IT). Hal ini dimaksudkan untuk mewujudkan lima peran Balai Penyuluh Pertanian (BPP) sebagai: a) pusat data dan informasi; b) pusat gerakan pembangunan pertanian; c) pusat pembelajaran; d), pusat konsultasi agribisnis; dan e) sebagai pusat pengembangan jejaring dan kemitraan. Kostratani merupakan pusat kegiatan pembangunan pertanian tingkat kecamatan, yang merupakan optimalisasi tugas, fungsi dan peran BPP dengan memanfaatkan IT dalam mewujudkan kedaulatan pangan nasional.

Undang-Undang Nomor 16 Tahun 2006 tentang Sistem Penyuluhan Pertanian, Perikanan dan Kehutanan (SP3K) melalui Pasal 4 mengamanatkan bahwa fungsi sistem penyuluhan adalah memfasilitasi proses pembelajaran pelaku utama dan pelaku usaha penyuluhan. Berbagi metode dapat dilakukan untuk meningkatkan pengetahuan dan pemahaman penyuluh mengenai materi penyuluhan seperti ahlnya dilakukan melalui pertemuan dan pelatihan. Menurut Sastradipoera (2006) konsep pelatihan sebagai salah satu bentuk proses pembelajaran yang berhubungan dengan upaya pengubahan tingkah laku sumber daya manusia agar sesuai dan memadai untuk kebutuhan dan tujuan tertentu.

Kegiatan temu tugas, merupakan salah satu media pertemuan dan pelatihan diantara peneliti penyuluh Badan Penelitian dan Pengembangan Pertanian (Balitbangtan) dengan penyuluh didaerah untuk mensinergikan upaya penderasan hilirisasi inovasi teknologi Balitbangtan kepada pengguna. Untuk melihat keefektivan kegiatan temu tugas 
Prosiding Seminar Nasional Pembangunan dan Pendidikan Vokasi Pertanian

Politeknik Pembangunan Pertanian Manokwari, 14 November 2020

e ISSN : 2774-1982

ini maka dilakukan suatu evaluasi sebagai upaya untuk mengukur sejauhmana keberhasilan kegiatan temu tugas yang telah dilaksanakan. Menurut Suwarto (1999), efektivitas artinya adanya efek (pengaruh, akibat, dan kesan) pada penggunaan metode/cara, sarana/alat dalam melaksanakan aktivitas sehingga berhasil guna (mencapai hasil yang optimal). Analisis digunakan untuk mengetahui efektivitas kegitan temu tugas terhadap peningkatan pengetahuan peserta. Dalam hal membuat analisis, perlu diselidiki apakah kegiatan yang dilaksanakan membawa efek yang diharapkan sesuai dengan tujuan yang telah ditetapkan dengan menerapkan kriteria yang dapat dipertangungjawabkan (Winkel, 2004).

\section{METODE}

Kegiatan temu tugas peneliti penyuluh Balitbangtan dengan penyuluh daerah di Provinsi Kalimantan Tengah ini dilaksanakan di Aula BPTP Kalimantan Tengah, Jl G.Obos KM 5 Palangka Raya pada tanggal 30-31 Januari 2020. Responden sebanyak 76 orang penyuluh yang berasal dari 14 kabupaten/kota di Provinsi Kalimantan Tengah. Jenis data yang digunakan adalah data primer yang meliputi usia, jenis kelamin dan tingkat pendidikan peserta. Metode pengambilan data dengan menggunakan wawancara terstruktur dengan kuesioner yang berisi daftar pertanyaan yang berhubungan dengan kostratani.

Untuk menguji tingkat pengetahuan peserta temu tugas dilaksanakan pengisian kuesioner yang sama sebelum pelaksanaan temu tugas (pre-test) dan sesudah pelaksanaan temu tugas (post-test). Untuk mengetahui tingkat signifikansi perlakuan dari peserta temu tugas sebelum dan sesudah pelaksanaan kegiatan dilakukan uji t-Test: Paired Two Sample for Means (Hendayana, 2014).

\section{HASIL DAN PEMBAHASAN}

\section{Karakteristik Peserta Temu Tugas}

Peserta kegiatan temu tugas adalah kepala bidang yang menangani penyuluhan dan koordinator penyuluh di wilayah Provinsi Kalimantan Tengah. Adapun karakteristik yang merupakan data primer meliputi usia, jenis kelamin dan tingkat pendidikan peserta (Tabel 1). Berdasarkan pada hasil kuesioner diperoleh data bahwa responden yang berusia 31-40 tahun berjumlah 26 orang (34,21\%), responden yang berusia 41-50 tahun berjumlah 17 orang $(22,37 \%)$ dan responden yang berusia antara 51-60 tahun. Hanya satu orang responden (1,32\%) yang berusia antara 21-30 tahun. Usia terendah responden adalah 26 tahun dan usia tertinggi mencapai 60 tahun. Hal ini menujukkan bahwa rata-rata usia penyuluh yang hadir pada kegiatan temu tugas masih berusia produktif, sebagaimana 
Prosiding Seminar Nasional Pembangunan dan Pendidikan Vokasi Pertanian

Politeknik Pembangunan Pertanian Manokwari, 14 November 2020

e ISSN : 2774-1982

dalam Soekartawi (1988), yang menyatakan bahwa usia produktif berada dibawah 65 tahun.

Tabel 1. Karakteristik responden peserta temu tugas peneliti penyuluh Balitbangtan dan penyuluh daerah di Aula BPTP Kalteng, 30-31 Januari 2020

\begin{tabular}{llccc}
\hline No. & Karakteristik & Kelompok & Jumlah (orang) & Persentase (\%) \\
\hline 1. & Usia & $21-30$ tahun & 1 & 1,32 \\
& & $31-40$ tahun & 26 & 34,21 \\
& & $41-50$ tahun & 17 & 22,37 \\
& & $31-60$ tahun & & 42,11 \\
2. & \multirow{2}{*}{ Jenis Kelamin } & Laki-laki & 56 & 73,68 \\
& & Perempuan & 20 & 26,32 \\
3. & Tingkat Pendidikan & SLTA & 6 & 7,89 \\
& & D3 & 5 & 6,58 \\
& & D4 & 9 & 11,84 \\
& & Sarjana & 52 & 68,42 \\
& & & & 5,26 \\
\end{tabular}

Sumber: Data Primer, 2020

Berdasarkan tabel 1 diperoleh data mengenai jenis kelamin peserta temu tugas, dimana mayoritas peserta berjenis kelamin laki-laki yaitu sebanyak 56 responden $(73,68 \%)$ dan sebanyak 20 responden $(426,32 \%)$ berjenis kelamin perempuan. Karakteristik yang lain adalah tingkat pendidikan penyuluh, dimana menurut Van den Ban (1999), tingkat pendidikan sangat membantu agen penyuluhan untuk mengambil keputusan. Mayoritas responden berpendidikan setingkat sarjana yang mencapai 68,42\% atau 52 responden. Sebanyak 4 responden $(5,26 \%)$ bahkan sudah memperoleh pendidikan hingga pasca sarjana. Sedangkan responden yang mempunyai tingkat pendidikan D4 sejumlah 9 orang $(11,84 \%)$, D3 sejumlah 5 orang $(6,58 \%)$ dan peserta yang hanya berpendidikan sampai SLTA sejumlah 6 orang $(7,89 \%)$. Dari hasil ini didapatkan data bahwa tingkat pendidikan penyuluh pertanian di Provinsi Kalimantan Tengah sudah masuk pada kategori yang tinggi. Tingkat pendidikan yang tinggi relatif lebih cepat dalam menerima informasi dan mengadopsi teknologi inovasi baru (Soekartawi, 1988). Menurut Nursalam dan Parini (2001), semakin tinggi tingkat pendidikan seseorang maka akan semakin mudah menerima informasi sehingga semakin banyak pula pengetahuan yang dimiliki. 
Prosiding Seminar Nasional Pembangunan dan Pendidikan Vokasi Pertanian

Politeknik Pembangunan Pertanian Manokwari, 14 November 2020

e ISSN : 2774-1982

\section{Analisis Tingkat Pengetahuan Penyuluh}

Materi penyuluhan pertanian adalah segala isi (content) yang terkandung dalam setiap kegiatan penyuluhan pertanian. Jadi, ilmu sebagai materi penyuluhan yang disampaikan kepada pengguna, baik penyuluh sendiri maupun stakeholder yang lain dapat berupa pengetahuan, dalam hal ini materi yang disampaikan pada kegiatan temu tugas meliputi informasi tentang kegiatan Kostratani seperti Peraturan Menteri Pertanian Nomor 49 tahun 2019 yang mengatur mengenai Komando Strategis Pembangunan Pertanian.dan implementasi dilapangan.

Untuk mengetahui tingkat pengetahuan peserta temu tugas dilakukan evaluasi melalui pres-test dan post-test. Setiap peserta diberikan 10 pertanyaan yang sama dengan nilai maksimal 10 apabila jawaban yang diberikan benar semua. Dilakukan pemeringkatan hasil nilai menjadi tiga tingkatan pengetahuan yaitu:

1. Tingkat pengetahuan rendah ( $<5$ jawaban benar)

2. Tingkat pengetahuan sedang (5-7 jawaban benar)

3. Tingkat pengetahuan tinggi (8-10 jawaban benar)

Hasil tabulasi dan pengolahan data pre-test dan post-test peserta temu tugas Kostratani tersaji pada tabel 2.

Tabel 2. Tingkat pengetahuan responden sebelum (pre-test) dan sesudah (post-test) kegiatan temu tugas Kostratani di Kalimantan Tengah, 2020

\begin{tabular}{llcccc}
\hline \multirow{2}{*}{ No. } & \multicolumn{1}{c}{ Kategori } & \multicolumn{2}{c}{ Pre-test } & \multicolumn{2}{c}{ Post-test } \\
\cline { 3 - 6 } & Jumlah (orang) & Persentase (\%) & Jumlah (orang) & Persentase (\%) \\
\hline 1. & $\begin{array}{l}\text { Tingkat pengetahuan } \\
\text { rendah }\end{array}$ & 7 & 9,21 & 0 & 0 \\
2. & $\begin{array}{l}\text { Tingkat pengetahuan } \\
\text { sedang }\end{array}$ & 29 & 38,16 & 4 & 5,26 \\
3. & $\begin{array}{l}\text { Tingkat pengetahuan } \\
\text { tinggi }\end{array}$ & 40 & 52,63 & 72 & 94,74 \\
\hline
\end{tabular}

Sumber: Data primer, 2020

Dari tabel 2, dapat diketahui tingkat pengetahun responden pada saat sebelum pelaksanaan kegiatan temu tugas atau saat pre-test. Sejumlah 7 responden $(9,21 \%)$ berada pada tingkat pengetahun rendah, 29 peserta $(38,16 \%)$ berada pada tingkat pengetahuan sedang dan sejumlah 40 peserta $(52,63 \%)$ berada pada tingkat pengetahuan tinggi. Hasil berbeda terlihat pada saat post-test dimana mayoritas responden berada pada tingkat pengetahuan tinggi dengan jumlah mencapai 72 orang $(94,74 \%)$. Sejumlah 4 responden 
Prosiding Seminar Nasional Pembangunan dan Pendidikan Vokasi Pertanian

Politeknik Pembangunan Pertanian Manokwari, 14 November 2020

e ISSN : 2774-1982

$(5,26 \%)$ berada pada tingkat pengetahuan sedang dan tidak terdapat responden yang berada pada tingkat pengetahuan yang rendah.

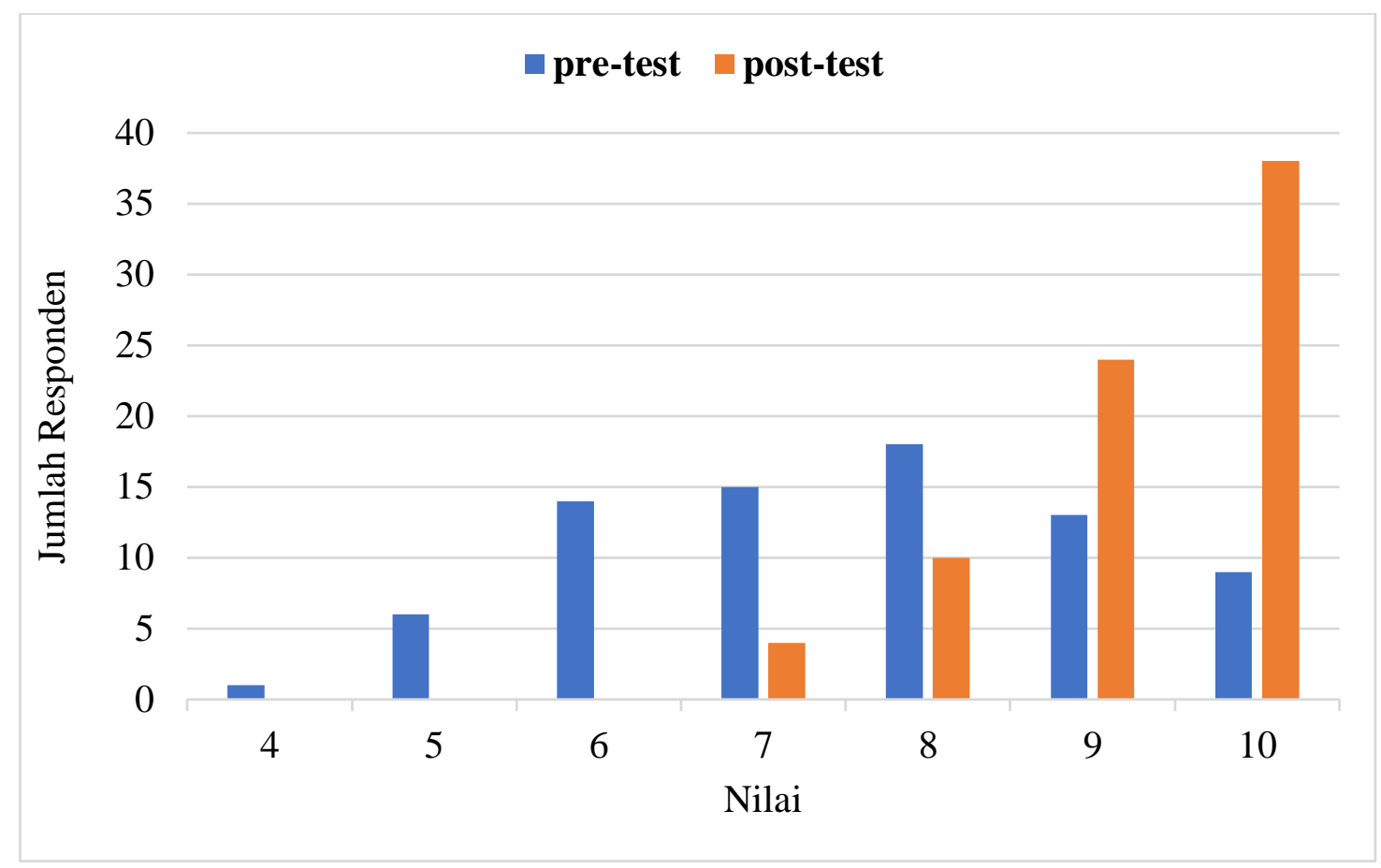

Gambar 1. Nilai responden sebelum dan sesudah pelaksanaan temu tugas

Berdasarkan pada gambar 1. dapat diketahui bahwa sebagian besar responden mendapatkan nilai 8 pada saat pre-test dengan jumlah 18 responden $(23,68 \%)$. Nilai paling kecil diperoleh responden pada saat pre-test adalah 4 dengan jumlah satu orang responden dan nilai tertinggi 10 dengan jumlah 9 responden. Hasil yang berbeda diperolah pada saat post-test, dimana mayoritas peserta mendapatkan nilai 10 dengan jumlah mencapai 38 responden (50\%). Sedangkan, nilai paling kecil yang diperoleh peserta pada saat post-test adalah 7 dengan jumlah 4 orang responden. Pergeseran mayoritas nilai peserta ini diyakini sebagai dampak dari pola komunikasi yang disampaikan oleh narasumber yang mampu menggugah pola pikir dan menambah pengetahuan penyuluh mengenai materi Kostratani. Sebagaimana dijelaskan oleh Effendy (2002) bahwa komunikasi adalah proses penyampaian suatu pesan oleh seseorang kepada orang lain untuk memberitahu atau untuk mengubah sikap, pendapat, atau perilaku baik langsung secara lisan, maupun tak langsung melalui media. De Fleur (1982) yang dikutip oleh Cangara (2006) menerangkan bahwa akibat dari proses komunikasi terjadi pada pengetahuan, sikap dan tingkah laku seseorang sehingga akibat dapat diartikan sebagai perubahan atau penguatan keyakinan pada 
Prosiding Seminar Nasional Pembangunan dan Pendidikan Vokasi Pertanian Politeknik Pembangunan Pertanian Manokwari, 14 November 2020

e ISSN : 2774-1982

pengetahuan, sikap dan tindakan seseorang sebagai akibat dari penerimaan pesan atau informasi.

Hasil jawaban responden dari 10 soal yang diberikan pada saat pre-test dan posttest untuk setiap soal dengan jawaban yang benar dapat terlihat pada gambar 2.

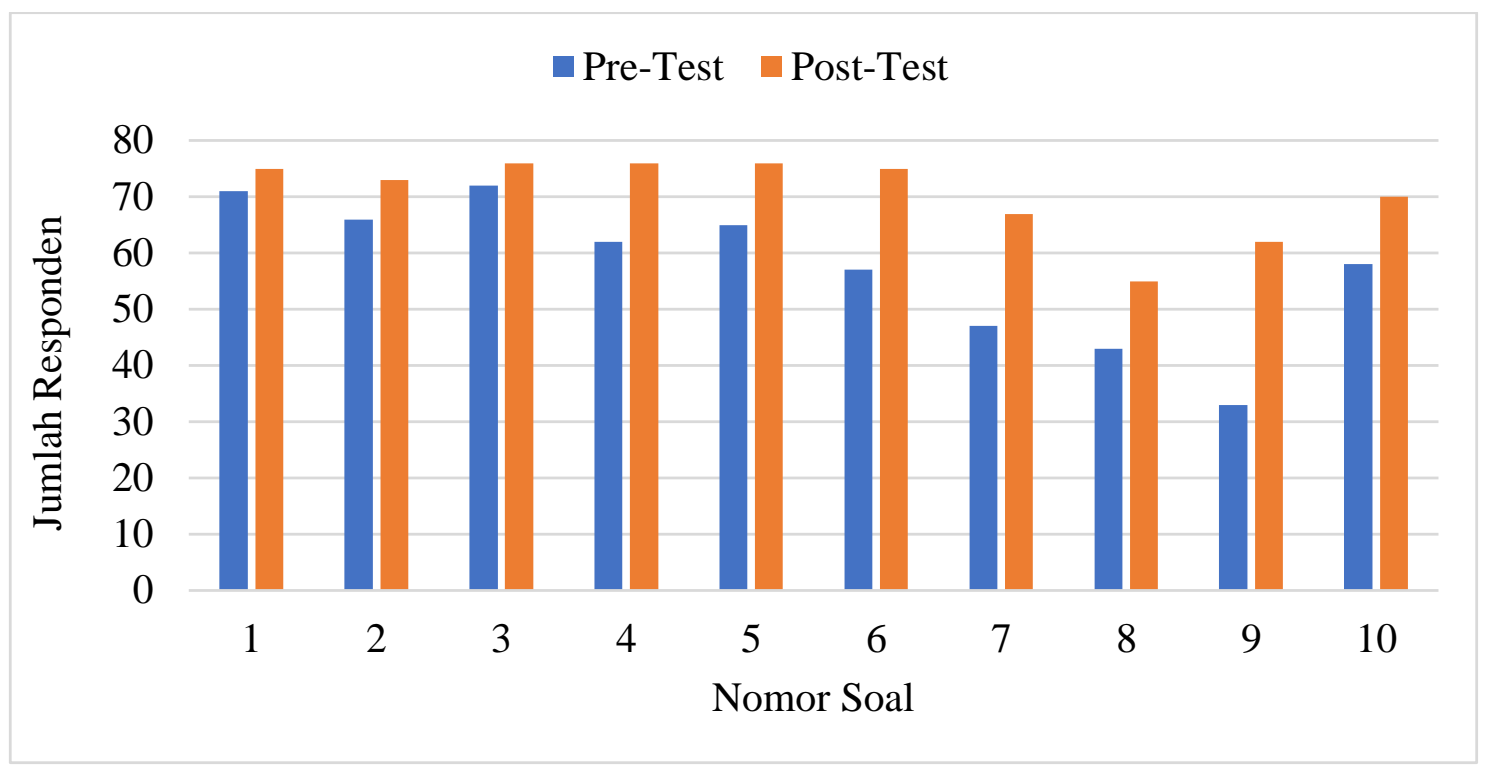

Gambar 2. Jumlah responden yang menjawab benar pada setiap nomor pertanyaan

Dari gambar 2 diperoleh data bahwa terjadi peningkatan jumlah responden yang menjawab benar untuk setiap nomor soal. Kenaikan tertinggi terdapat pada soal nomor 9, dari yang sebelum pelatihan hanya 33 responden $(43,42 \%)$ yang menjawab dengan benar naik 29 responden menjadi 62 responden $(81,58 \%)$. Soal nomor 9 berisi pertanyaan mengenai teknologi informasi yang digunakan pada alur penyampaian data pada kegiatan Kostratani yaitu pengguanan Agriculture Operational Room (AOR) dan Agriculture War Room (AWR) secara real time. Tidak terdapat satu soal pun yang mengalami penurunan jawaban yang benar. Hal ini menandakan bahwa pelatihan telah berhasil meningkatkan pengetahuan responden mengenai materi yang diberikan.

Hasil analisis yang dilakukan dengan menggunakan uji t-Test: Paired Two Sample for Means diperoleh data nilai t Stat $7.26>$ t Critical two-tail 1.99 (Tabel 3.), hal ini menunjukkan bahwa terdapat perbedaan nyata pada pengetahuan responden sebelum diadakan pelatihan dan sesudah diadakan pelatihan. Dari tabel 3 juga diketahui bahwa nilai rata-rata peserta temu tugas untuk setiap soal dengan jawaban benar naik dari yang sebelum pelaksanaan temu tugas sebesar 7.55 menjadi 8.82 sesudah pelaksanaan temu tugas. Dari hasil analisis ini dapat dijabarkan bahwa kegiatan temu tugas peneliti penyuluh Balitbangtan dengan penyuluh daerah dalam mendukung Kostratani yang diselenggarakan 
Prosiding Seminar Nasional Pembangunan dan Pendidikan Vokasi Pertanian Politeknik Pembangunan Pertanian Manokwari, 14 November 2020

e ISSN : 2774-1982

di Aula BPTP Kalimantan Tengah pada tanggal 30-31 Januari 2020 efektif meningkatkan pengetahuan penyuluh mengenai materi yang telah diberikan dengan metode ceramah dan diskusi.

Tabel 3. Hasil uji t-Test: Paired Two Sample for Means pre-test dan post-test temu tugas Kostratani di Kalimantan Tengah, 2020

\begin{tabular}{lrr}
\hline & Pre Test & Post Test \\
\hline Mean & 7.552631579 & 8.815789474 \\
Variance & 2.330526316 & 1.885614035 \\
Observations & 76 & 76 \\
Pearson Correlation & 0.456275957 & \\
Hypothesized Mean Difference & 0 & \\
df & 75 & \\
$\mathrm{t}$ Stat & -7.256088662 & \\
$\mathrm{P}(\mathrm{T}<=\mathrm{t})$ one-tail & $1.53268 \mathrm{E}-10$ & \\
$\mathrm{t}$ Critical one-tail & 1.665425373 & \\
$\mathrm{P}(\mathrm{T}<=\mathrm{t})$ two-tail & $3.06536 \mathrm{E}-10$ & \\
$\mathrm{t}$ Critical two-tail & 1.992102154 & \\
\hline
\end{tabular}

Sumber: Analisis data primer, 2020

\section{KESIMPULAN}

Hasil evaluasi kegiatan temu tugas peneliti penyuluh Balitbangtan dengan penyuluh daerah dalam mendukung program Kostratani di Provinsi Kalimantan Tengah yang dilaksanakan pada tanggal 30-31 Januari 2020 di Aula BPTP Kalimantan dapat disimpulkan bahwa telah terjadi peningkatan terhadap pengetahuan para penyuluh pertanian peserta temu tugas mengenai materi Kostratani.

\section{UCAPAN TERIMA KASIH}

Ucapan terima kasih penulis sampaikan kepada Kepala BPTP Kalimantan Tengah yang mendukung kegiatan temu tugas, baik dari segi kebijakan maupun pendanaan serta semua penyuluh dan peneliti BPTP Kalimantan Tengah yang mensupport kegiatan sehingga dapat terlaksana dengan baik.

\section{DAFTAR PUSTAKA}

A.W.Van den Ban \& H.S.Hawkins. (1999). Penyuluhan Pertanian. Penerbit Kanisius. Yogyakarta.

Bahua M.I. (2010). Faktor-Faktor Yang Mempengaruhi Penyuluh Pertanian dan Dampaknya Pada Perilaku Petani Jagung di Provinsi Gorontalo. Disertasi.Tidak Dipublikasikan. Sekolah Pascasarjana IPB. Bogor. 
Prosiding Seminar Nasional Pembangunan dan Pendidikan Vokasi Pertanian

Politeknik Pembangunan Pertanian Manokwari, 14 November 2020

e ISSN : 2774-1982

Cangara, Hafied. (2006). Pengantar Ilmu Komunikasi. Rajagrafindo Persada. Jakarta.

Effendy, Onong Uchjana. (2002). Dinamika Komunikasi. Remaja Rosdakarya. Bandung.

Hendayana, Rachmat. (2014). Persepsi dan Adopsi Teknologi Teori dan Praktik Pengukuran. Materi Peningkatan Kapasitas Sumberdaya Peneliti Sosial Ekonomi dalam Analisis Sosial Ekonomi dan Kebijakan Pertanian. Bogor.

Kushartanti E., G. Retno D W., Umi P A., Haris S., M.Prama Y., Rahina K., Tini S K., Sudi M., Sad H P., M.Yusron., Sumedi, Mewa A., Maesti M., Achmad D., Rachmat H., \& Ume H. (2018). Pedoman Pelaksanaan Peningkatan Kapasitas Penyuluh dan Diseminasi Inovasi Pertanian. Balai Besar Pengkajian dan Pengembangan Teknologi Pertanian. Bogor.

Nursalam \& Parini. (2001). Pendekatan Praktis Metodologi Riset Keperawatan. Salemba Mendika. Jakarta.

Nursyamsi, Dedy. (2020). Rumusan bimbingan teknis kapasitas dan kompetensi penyuluh pertanian PNS 2-4 Maret 2020. Depok, Jawa Barat.

Sastardipoera, Komarudin. (2006). Pengembangan dan Pelatihan, Suatu Pendekatan Manajemen SDM. Penerbit Kappa Sigma. Bandung.

Soekartawi. (1988). Prinsip Dasar Komunikasi Pertanian. Penerbit Universitas Indonesia. Jakarta.

Suwarto. (1999). Perilaku Keorganisasian. Universitas Atma Jaya Yogyakarta. Yogyakarta.

Suwarto. (2006). Undang Undang Republik Indonesia Nomor 16 Tahun 2006 Tentang Sistem Penyuluhan Pertanian, Perikanan, Dan Kehutanan.

Suwarto. (2019). Permentan nomor 49 tahun 2019 tentang Komando Strategis Pembangunan Pertanian

Winkel, W.S \& M.M. Sri Hastuti. (2004). Bimbingan dan Konseling di Institusi Pendidikan. Media Abadi. Yogyakarta. 